\title{
Recommendation for Sustaining the In-service Professional Development of Tertiary EFL Teachers
}

\author{
Junyi Meng \\ School of Foreign Languages, Institute of Social Technology, Suranaree University of Technology, Nakhon Ratchasima, \\ Thailand \\ Songphorn Tajaroensuk \\ School of Foreign Languages, Institute of Social Technology, Suranaree University of Technology, Nakhon Ratchasima, \\ Thailand \\ Sirinthorn Seepho
School of Foreign Languages, Institute of Social Technology, Suranaree University of Technology, Nakhon Ratchasima,
Thailand
}

\begin{abstract}
The increasing influence of English as a lingua franca or an international language has brought new trends of teaching English as a foreign language (TEFL). But on the way to these new trends some issues have inevitably appeared, and one of them is the continuity of EFL teachers' in-service professional development. This study aimed to investigate the opinions of the tertiary EFL teachers on the multilayered peer coaching model (the MPC Model) that they had employed for their in-service professional development, and make the recommendation of this model for sustaining tertiary EFL teachers' in-service professional development. The information was obtained from the EFL teachers at Guiyang University in China with the help of such instruments as observation, teacher's diary, the researcher's field note, questionnaire and interview, and the data were analyzed in both qualitative and quantitative methods. The results revealed that the tertiary EFL teachers had positive attitudes towards the MPC Model and it could be recommended as one of the effective tools for the tertiary EFL teachers to sustain their in-service professional development.
\end{abstract}

Index Terms-in-service professional development, tertiary EFL teachers, the multilayered peer coaching model, recommendation

\section{INTRODUCTION}

English is now used for international and intercultural purposes more extensively. In order to smooth the flow of English language use, to facilitate English language learning, and to reach the requirements of new trends in the field of teaching English as a foreign language (TEFL), EFL teachers are expected to update their professional knowledge and competence, and more importantly, to continue this updating through their in-service professional development.

Studies of teachers' professional development have identified the phases that the EFL teachers have to go through in the course of their careers. Tsui (2007) stated that some of the commonly identified phases included: 1) the survival phase, 2) a stabilization phase or a self-doubt phase, 3) an experimentation phase or a reassessment phase, and 4) a serenity phase. In these four different phases, the first and the last were found to be easily realized because they are two extremes of a teacher's career, while the in-between phases are quite dynamic because they may develop into either of the two situations: positive and negative. According to Fessler and Christensen (1992) and Huberman (1993a), if the experience in the survival phase is positive, there comes a stabilization phase; if it is negative, a self-doubt phase may occur. Likewise, in the third phase, if the teachers are highly motivated to try out new ideas, an experimentation phase may happen; if they are disappointed with the outcome, a reassessment phase may jump off. So it is obvious that achieving the positive results of these in-between phases is important and it is closely related to the teachers' in-service professional development which serves as the promoter to update the EFL teachers' professional knowledge and competence with the change of the society and the timely requirements of TEFL.

In-service professional development can be generally defined as the education to help EFL teachers develop their skills in the field of TEFL, and it usually takes place after a teacher begins his or her work responsibilities. Its importance has been discussed by many researchers for a long time, for example, from James (1973), who once stated that it is only through the growth of in-service training that this gulf between advancing knowledge and practice can be bridged, to Widden et al (1996) and Day (1999), who have claimed that the nature of teaching demands teachers to engage in utilizing this knowledge effectively and it needs continuing career-long professional development role of the teacher in changing contexts, then to Wan (2011), who ascertained that continuous professional development that serves 
as an ongoing process of education, training, learning and support activities engaged in by teachers alone or with others can enhance their knowledge and skills and enable them to consider their attitudes and approaches to the education of learners, and to improve the quality of learning and teaching. Therefore, EFL teachers throughout the world are greatly encouraged to have their in-service professional development.

China, since its education reform, has also encouraged its tertiary EFL teachers to carry out their professional development to meet its updated requirements of TEFL, such as, the "Syllabus for English Majors of Colleges or Universities" (revised in 2001) and the new "College English Curriculum Requirement" (issued in 2006). Tertiary EFL teachers in China can be generally divided into two groups: EFL teachers for non-English majors and EFL teachers for English majors. The former group focuses on teaching general English skills, namely, listening, speaking, reading, writing, and translating, and in most cases they have much heavier teaching load; the latter group deals with both general English skills teaching and specialized courses delivery such as English linguistics, American and British literature, translation between Chinese and English, culture studies, etc., and most of them have a specific research focus. Since the year of 1998, China has increased its college enrollment, during the 1996-2000 period there was a total enrollment of over 11 million, from 2001 to 2005 the number of university students would be up to 16 million (CERNET, 2001). It is evident that the workload has increasingly been heavier for both groups, which is found to contribute to the difficulties of their in-service professional development.

Besides, the implementation of in-service professional development is also faced with other difficulties. Ono and Ferreira (2010) have pointed out that many models of professional development do not achieve their ambitious learning goals. Other researchers (e.g. Fullan \& Hargreaves, 1996; Ball \& Cohen, 1999; Collinson \& Ono, 2001; Feiman-Nemser, 2001; Villegas-Reimers, 2003; Schwille \& Dembélé, 2007) found that traditional in-service teacher professional development programs are delivered in the form of workshops, seminars, conferences or courses, which have been criticized as being brief, fragmented, incoherent encounters that are decontextualised and isolated from real classroom situations. And the results in these studies (Zhang \& Li, 2003; Liu, 2005; Liu, 2006; Zheng, 2010) showed that Chinese EFL teachers are often trained in a theoretical, academic, or research-oriented way which makes them tend to be passive, and the theory-practice gap has always been criticized by school teachers when commenting on these training programs. In Wen and Ren' survey (2010), by reviewing the characteristics of the literature concerning the tertiary EFL teacher in-service professional development in China from the year of 1999 to 2009, they also found that many problems were linked to such limitations as being isolated from EFL classrooms and neglecting the teachers' demands.

Therefore, this study aimed to investigate the opinions of the tertiary EFL teachers on the multilayered peer coaching model (the MPC Model) that they had employed for their in-service professional development, and recommend this model for sustaining tertiary EFL teachers' in-service professional development. This study provided the answers to the following research questions:

1. Does the MPC Model help to sustain the tertiary EFL teachers' in-service professional development?

2. What are the tertiary EFL teachers' attitudes towards the MPC Model for their in-service professional development?

\section{The Multilayered Peer Coaching Model}

The MPC Model was developed for tertiary EFL teachers to have their in-service professional development. It refers to the practice of peer coaching within a team teaching context, which can offer teachers more opportunities to support one another in their work. In the TEFL setting, this means that teachers may experience two layers of collaboration. The first layer is team teaching in which four teachers can be involved as a team so that common issues and problems will be discussed and solved by pooling the ideas of the team members. The second layer is peer coaching where two dyads will be formed within the team so that the two peer teachers in each dyad will work together to reflect on current practices, expand, refine, and build new skills, share ideas; teach each other; conduct classroom research; or solve problems in the workplace. The working flowchart of the MPC Model was shown in Figure 1 below.

The MPC Model was developed based on the ADDIE Model, which is one of the most popular Instructional System Design (ISD) models and is characterized by its five generic and easily-followed phases: Analysis, Design, Development, Implementation and Evaluation. The first letter of the five phases forms the acronym "ADDIE". The "Analysis" phase is mainly for investigating the needs, clarifying the instructional problems, obtaining the relevant suggestions, and identifying the learning environment. The "Design" phase deals with learners, learning objectives, assessment instruments, content, lesson planning, and media selection. In the "Development" phase, the instructional designers and developers create and assemble the content assets that are blueprinted in the design phase. The "Implementation" phase offers a procedure for training the learners. The training usually includes the course curriculum, learning outcomes, method of delivery, and testing procedures, etc. In the "Evaluation" phase, two parts are involved: formative evaluation and summative evaluation. Formative evaluation is present in each stage of the ADDIE process. Summative evaluation includes tests designed for domain specific criterion-related referenced items and provides opportunities for feedback from the learners (See Figure 2). 


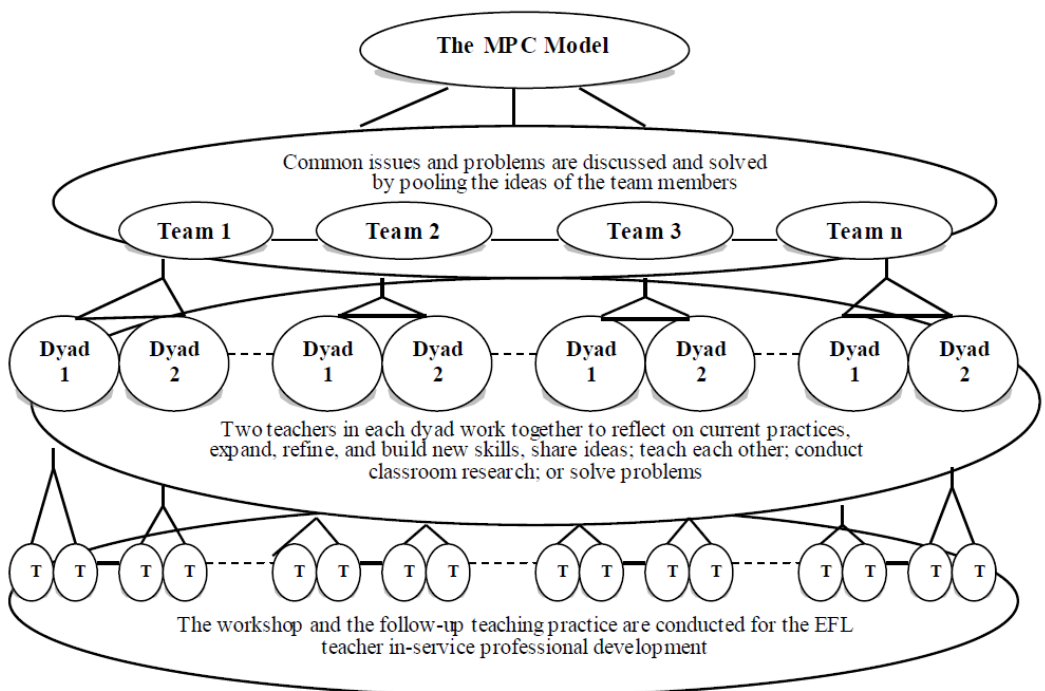

Figure 1. The Working Flowchart of the MPC Model

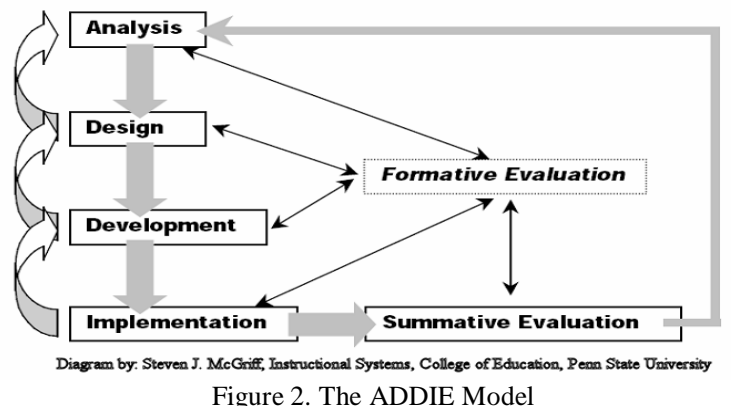

In developing the MPC Model, the researcher constructed its conceptual framework which was actually the operationalization of the ISD theory that the MPC Model followed in its development. The main ISD theory for the MPC Model was ADDIE, and in order to show the relationship between the phases of the MPC Model and those of ADDIE, the figure "the ADDIE correspondence with the MPC Model" was made. The top part of this figure was the ADDIE's phases, and the rest part was the MPC Model's conceptual framework. The dotted lines and the different shapes showed the match between them. The detail was presented in Figure 3 as follows:

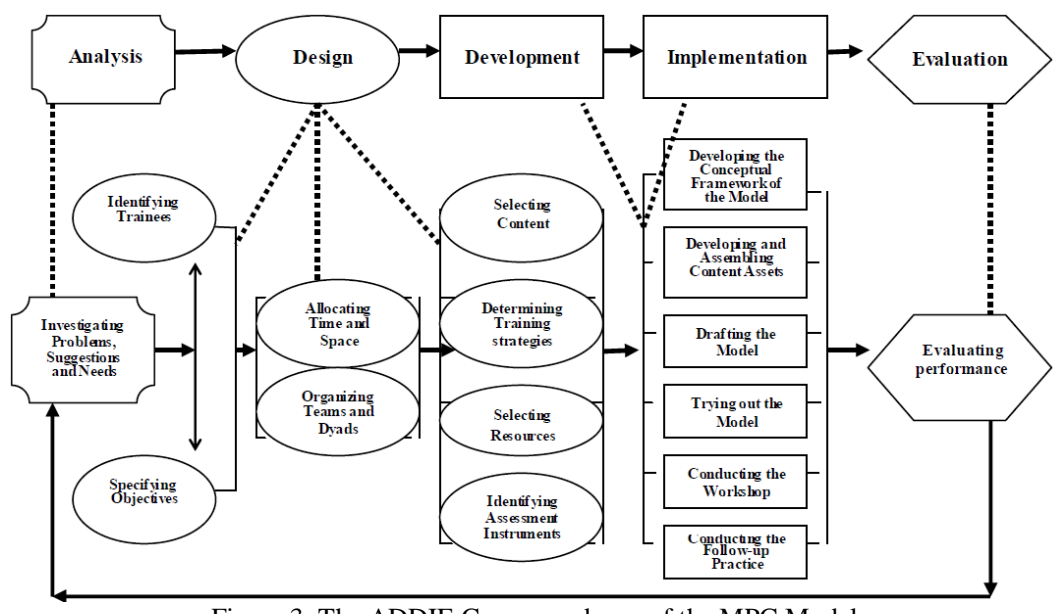

Figure 3. The ADDIE Correspondence of the MPC Model

The MPC Model also had its research procedure including five phases and 15 steps (See Figure 4). Each of the five phases with its own elements displayed the detailed process for developing the MPC Model.

Phase I: Needs Analysis

The purpose of this phase in this study helped the researcher determine to use questionnaire and interview in group for the tertiary EFL teachers' problems and suggestions on their in-service professional development, and obtained their needs of the MPC Model. Three experts from the fields of TEFL and education research checked the questionnaire items and interview questions. Their detailed results were shown in another academic paper by the same authors. 


\section{Phase II: Design of the model}

In this systematic and specific phase, the researcher firstly identified the trainees, wrote the training objectives and settled the training environment; then selected the training content, specified training methods and media; finally identified assessment instruments. All the steps in this phase were conducted based on the needs analysis in Phase I and with the consultation of the experts as well.

\section{Phase III: Development of the model}

In this critical phase, the researcher followed such steps to develop the MPC Model as follows. First, the conceptual framework for EFL teacher multilayered peer coaching training was developed. Second, the content of instruction was developed based on the analysis of needs done in Phase I. Third, the content of the training lessons was evaluated by the experts in the field of TEFL. Fourth, the MPC Model was drafted. Fifth, the MPC Model was tried out. Sixth, the model was finalized. The in-service tertiary EFL teachers' feedback and suggestions were considered. To determine the efficiency of the MPC Model, the tests were designed. The pre-test and the post-test were constructed with their items analysis and improvement.

\section{Phase IV: Implementation of the model}

In this practical phase, the researcher investigated the efficiency of the MPC Model by conducting the experiment. First, on the day before the experiment, the 12 teacher participants were pre-tested on their knowledge of both TEFL and the required teaching materials. Second, the teachers were grouped into three teams with two dyads in each based on their teaching duration. Third, the teachers received the training in the 3-day workshop by an external expert and the researcher. The training started with the expert's lecture on the new concept and updated knowledge of TEFL, and then the MPC Model was introduced by the researcher, after that, the teachers practiced the collaborative approach they had just learned. As soon as the workshop was over, the teachers moved on to the follow-up teaching by practicing the multilayered peer coaching in the intact classes for 15 weeks. Fourth, after each lesson, the teachers wrote the teacher's diary to show their procedure and feedback. Meanwhile, the researcher observed the teachers' classroom teaching and cooperation, and kept her field notes after each lesson. Fifth, after the experiment, a post-test was given to the teachers. Sixth, the questionnaires were conducted to find out the students' opinions on the instruction given by the teachers involved in the MPC Model and the teachers' opinions on the MPC Model. Finally, the interview was adopted to obtain the in-depth information about the teachers' attitudes towards the MPC Model.

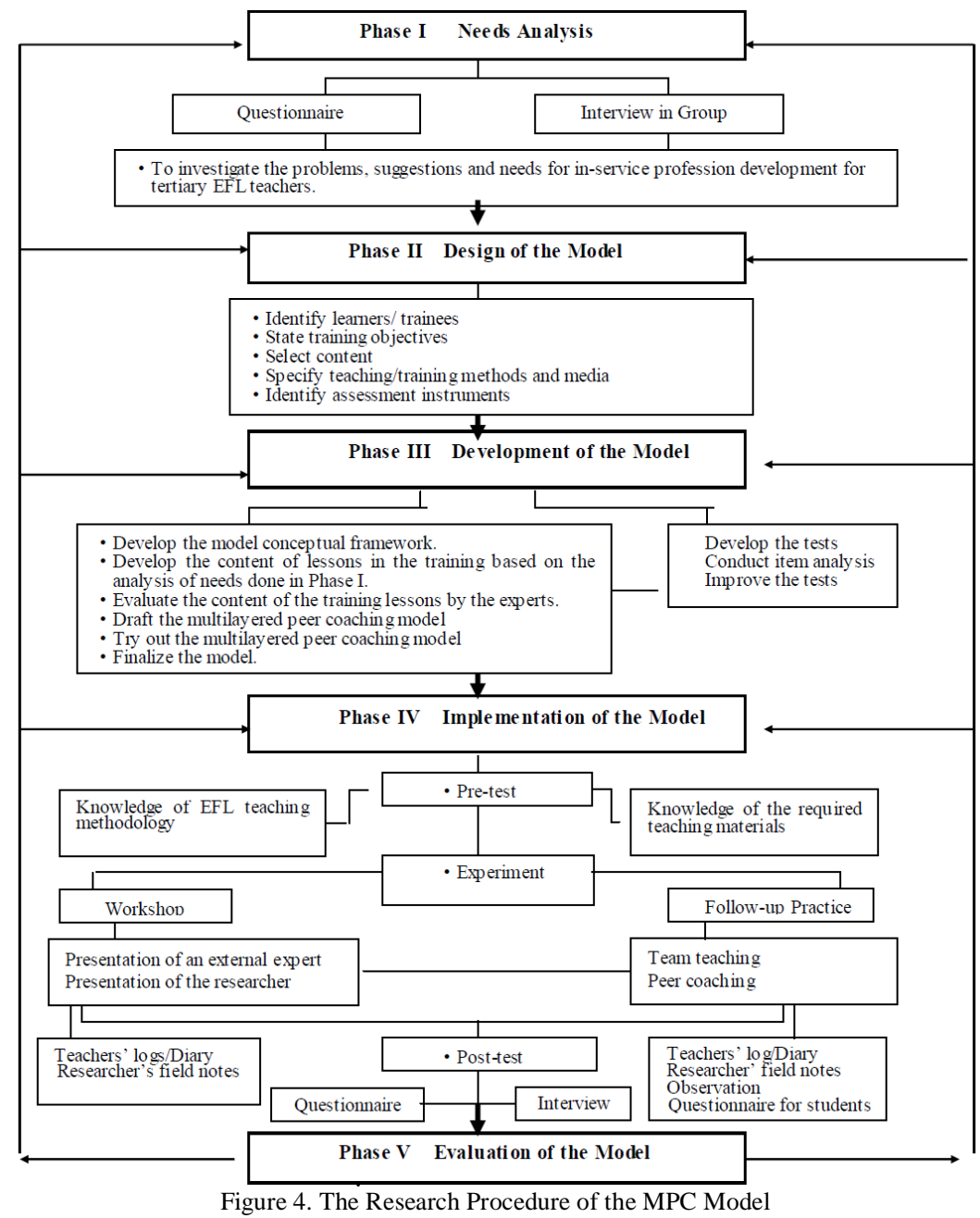




\section{Phase V: Evaluation of the model}

In this indispensable phase, the researcher measured the effectiveness of the MPC Model and the teachers' performance in it. Throughout the entire instruction design process, whether within phases, or between phases, or after the implementation, the evaluation was conducted. Starting with investigating the needs for the MPC Model, the evaluation was carried out by determining the design of instruction, observing the training instruction and the practice of this model, investigating the teachers' achievement in their in-service professional development, identifying the teacher's attitudes towards the MPC Model and the students' opinions on the instruction guided by the MPC Model.

To summarize, the MPC Model served as an effective training support tool for tertiary EFL teachers to have or sustain their in-service professional development. Being rooted in the real teaching context and in daily teaching, the MPC Model laid emphasis on the real demands of the trainees. With the multilayered peer coaching practice, the teachers could have their in-service professional development in continuity. The MPC Model helped to realize the goal that where there was teaching, there was the teachers' in-service professional development.

\section{RESEARCH METHODOLOGY}

\section{A. Participants}

12 EFL teachers and 105 second-year EFL students from the School of Foreign Languages at Guiyang University in China participated in this study. The teachers teach the course "Comprehensive English" and the students are in the intact classes. The participants were selected on the basis of purposiveness and availability.

\section{B. Instruments}

5 instruments were employed for data collection, namely, non-participant observation, teacher's dairy, the researcher's field note, a questionnaire and a semi-structured interview.

- The observation checklist was designed in the observation to find out the steps that the teacher participants followed in their teaching procedure in class, and its items were checked by the experts for validity and reliability;

- The teacher's diary was used for the teacher participants to record their teaching and cooperation, and to keep their reflection as well;

- The researcher' field note was for the researcher of this study to write down what she observed in the teacher participants' classroom teaching and after-class cooperation;

- A questionnaire was designed to investigate the teacher participants' opinions on the MPC Model. Three parts were included in this questionnaire. Part I was the participants' personal information. Part II was the statements on the opinions the teacher participants have on the MPC Model. Part III consisted of the open-ended questions about their attitudes towards the MPC Model. 5-point Likert scale was used to design the closed-ended questions according to their level of agreement. Values on the scale were strongly disagree, disagree, uncertain, agree, and strongly agree. Internal consistency of the questionnaires was checked by utilizing 10 respondents for a pilot. The respondents' data were analyzed by the Coefficient of Cronbach's statistical technique with the help of the SPSS, a computerized software for social sciences;

- A semi-structured interview was employed to find more in-depth information about the teacher participants' attitudes towards the MPC Model. Some related questions were offered, which were checked by the experts for validity and reliability.

\section{Data Collection}

While collecting the data, the researchers observed each teacher participant's classroom teaching for 15 hours (one hour per week) by filling out the observation checklists. Meanwhile, the teacher participants were asked to write the teacher's diary to reflect their classroom teaching and after-class cooperation, in which the procedure of their peer coaching, especially the application of some new strategies by the peer teachers of each dyad before, during, and after the classroom teaching were recorded. Besides, the researcher's field note was done each time when the researchers observed the classroom teaching and the after-class cooperation. Time was given for the researcher to work on it on the spot, and she may also work on it by more description at home. After the teacher participants implemented the MPC Model, all of them responded to the questionnaire with both closed-end and open-ended questions. Finally, the 12 teacher participants were interviewed for their attitudes towards the MPC Model.

\section{Data Analysis}

\section{Quantitative Data Analysis}

In terms of the quantitative data from the Likert Questionnaire and the observation checklists, the statistical way was adopted for analyzing the data, exactly, the teachers' responses in the questionnaire were analyzed by the frequencies for the level of their agreements, and the checklists were done by the frequencies for the occurrence of the teaching steps.

2. Qualitative Data Analysis

Regarding the qualitative data from the open-ended questions in the questionnaire, the teacher's diary, the researcher's field note, and interview, the qualitative analysis method, exactly, content analysis, was employed. While 
analyzing the data from the open-ended questionnaire, the teacher's diary, and the researcher's field note, the data were already the written texts and then could be directly progressed according to the steps of content analysis. While analyzing the data from the interview, the audio-taped data were firstly transcribed with several times of listening in order to have their reliability, and then the transcribed data followed the other steps of content analysis.

\section{RESUlts}

After analyzing the collected data, the researcher tried to relate the results to the research questions in this study. In response to Research Question 1, the results were presented based on the instruments respectively.

\section{A. Results from the Observation}

The researchers observed each of the teacher participants in his or her classroom teaching for 15 hours (one hour per week) for the purpose of investigating whether the teachers could go through the teaching procedure completely and smoothly, and what steps were more frequently or less frequently taken in the procedure. It was found that seven steps in the teaching procedure were taken. The results of the observation checklist were shown as follows:

TABLE 1:

THE RESULTS OF OBSERVATION CHECKLIST FOR TEACHING PROCEDURE

\begin{tabular}{cccccccc}
\hline Teacher & Pre view & $\begin{array}{c}\text { Teacher's } \\
\text { presentation }\end{array}$ & Q\&A & $\begin{array}{c}\text { Observation } \\
\text { Discussion }\end{array}$ & $\begin{array}{c}\text { Items } \\
\text { Other } \\
\text { activities }\end{array}$ & Summary & Assignment \\
\hline T1 & 15 & 15 & 15 & 12 & 5 & 15 & 15 \\
T2 & 15 & 15 & 15 & 11 & 5 & 15 & 15 \\
T3 & 15 & 15 & 15 & 9 & 6 & 15 & 15 \\
T4 & 15 & 15 & 15 & 10 & 4 & 15 & 15 \\
T5 & 15 & 15 & 15 & 8 & 5 & 15 & 15 \\
T6 & 15 & 15 & 15 & 13 & 6 & 15 & 15 \\
T7 & 15 & 15 & 15 & 11 & 7 & 15 & 15 \\
T8 & 15 & 15 & 15 & 12 & 4 & 15 & 15 \\
T9 & 15 & 15 & 15 & 10 & 5 & 15 & 15 \\
T10 & 15 & 15 & 15 & 8 & 6 & 15 & 15 \\
T11 & 15 & 15 & 15 & 9 & 7 & 15 & 15 \\
T12 & 15 & 15 & 15 & 8 & 5 & 15 & 15 \\
Mean & $\mathbf{1 5 . 0 0}$ & $\mathbf{1 5 . 0 0}$ & $\mathbf{1 5 . 0 0}$ & $\mathbf{1 0 . 0 8}$ & $\mathbf{5 . 4 2}$ & $\mathbf{1 5 . 0 0}$ & $\mathbf{1 5 . 0 0}$ \\
SD & $\mathbf{0 . 0 0}$ & $\mathbf{0 . 0 0}$ & $\mathbf{0 . 0 0}$ & $\mathbf{1 . 7 3}$ & $\mathbf{0 . 9 9}$ & $\mathbf{0 . 0 0}$ & $\mathbf{0 . 0 0}$ \\
\hline
\end{tabular}

Table 1 showed that in the seven steps, such steps as preview, teacher's presentation, questions and answers, summary, and assignment were completed in each period for 15 weeks with the mean scores of 15.00 and the standard deviation of 0.00. So these five main steps were more frequently used. Regarding the other two steps: discussion and other activities, the teachers were less frequently used with the mean scores of 10.08 and 5.42 and the standard deviation of 1.73 and 0.99 respectively. For the discussion, it was found that the teacher could not do it in each period, and for the other activities, the teacher only used them in response to some unworkable activities. Obviously, these seven steps formed a cycle to complete a whole period of classroom teaching. The time allotment for each step was generally accepted and utilized well by the teacher participants. Therefore, the complete and smooth teaching procedure implied the teachers' improvement of teaching ability.

\section{B. Results from the Teacher's Diary}

The results from the teacher's diary were presented with two themes: 1) what they did during their daily teaching and cooperation; and 2) how did they feel about their work and their cooperation with the help of MPC Model.

Firstly, it was found that in the classroom teaching, all teachers shared similar main teaching steps with similar time allotment, and laid more emphasis on the interactions. However, they used different teaching aids for the same purpose, and showed their different focuses in each step. In the after-class cooperation, the peer teachers in each dyad had the cooperation mainly concerning four parts: teaching planning, material analyzing, students' problems, and classroom research; the four teachers in each team worked together for such purposes as the problems the peer teachers could not solve and the topics of classroom research. However, the peer teachers in each dyad had their own cooperation focus.

Secondly, the teachers felt: a) the teachers' cooperation in the multilayered layered context guided them to plan their lessons purposively and design teaching activities with the updated professional knowledge. A teacher wrote:

"I finished the teaching plan in the class accordingly, feeling very successful. In this lesson, I paid more attention to making the students grasp the usage of the new words and to their progress in language abilities. While in after-class cooperation, the teaching partner raised these suggestions for the class: first, it is not enough to tell the students that the conjunctions are important for writing. It should be explained with some examples, such as, the contrast of the two passages, and then make the students writing a passage with the conjunctions; second, when the teacher deals with the exercises of translation, some related translation skill should be generalized to the students. In real classroom teaching practice, these suggestions work." (T1)

And b) the cooperation in MPC Model helped them to solve problems both in classroom teaching and classroom research. An example was as follows: 
"Further reading is a good opportunity to train the students' critical thinking. But the problem is that the material the textbook offered for further reading in each unit is quite close in the standpoint to the text the students learned. So, in today's cooperation, I raised this question, and together with the others, we have searched more information, and next week we can supply more materials from different angles for the students to do further reading. Our cooperation is really helpful." (T2)

In addition, c) they could be more exposed to the professional knowledge while cooperating with peers and team members, such terms as CLT, TBLT, CALL, etc, were often mentioned in after-class cooperation. Here was one of the examples:

"Language work and text explanation are the essential scenes of this course. It is thus natural to take up most of the course time. Although it is not easy to find a short-cut in this part, a wise selection of exercises which are aimed at checking the students' acquisition is possible. What should be selected for the required exercise has been discussed in the cooperation time, and those selected may have a good conclusion on such language work. TBLT helps us to design the tasks, CLT offers us a approach to the goal, and CALL is what we can use to present our lesson... " (T3)

To conclude, it can be said that after the teachers' cooperation in the MPC Model, they found the advantages of this model, and were willing to sustain their in-service professional development in their daily work.

\section{Results from the Researcher's Field Note}

The researcher sat in the classroom and the discussion of the dyads and the teams in turn each week, and found that the teachers' cooperation both in class and after class could be grouped into two parts: things in common and things in difference. The results were showed as follows:

For the things in common, it was found that, a) in classroom teaching, all the teachers in six dyads went though the main five steps smoothly from preview, teacher's presentation, questions and answers, summary and assignment during the teaching procedure each time, and sometimes carried out the steps discussion and other activities in between. One of the peer teachers in a dyad who was good at teaching a specific skill gave the class the relevant content, and the other teacher sat to observe him or her. When the peer teachers were in class simultaneously, both of them answered the students' questions sometimes in turn and sometimes at the same time. The class with the appearance of the peer teachers led to more interaction and practice opportunities. b) In the after-class cooperation, the teachers' cooperation was generally practical and pleasant. The cooperation within the peer teachers of a dyad was mainly for the detailed issues on teaching preparation, classroom teaching, and the research on the classroom teaching, and the cooperation within the four teachers of a team was mainly for the problems that a dyad failed to solve, and the discussion for the classroom research.

For the things in difference, it was found that, a) in classroom teaching, each dyad had its own characteristics, the peer teachers had different strategies for their presentation in class, they had their own supplementary materials for students' further study, and they faced different problems from the students. b) In after-class cooperation, each dyad had its own focus on the research related to the classroom teaching. The peer teachers in some dyads could easily agree with each other in their discussion while some other dyads had to negotiate before reaching their agreement. Each dyad designed their teaching tasks based on their understanding of TEFL perspectives and methods.

Therefore, the results revealed that the teachers' cooperation in the MPC Model was improving the teachers' professional knowledge and teaching ability.

In response to Research Question 2, two instruments were employed for data collection, and their results were shown respectively.

\section{Results from the Questionnaire}

The investigation was conducted through the questionnaire that was made up of both closed-ended and open-ended questions. Firstly, according to their level of agreement, the teacher participants rated on 5-point Likert scale to show their opinions on the MPC Model for their in-service professional development.

TABLE 2:

THE RESULTS OF TERTIARY EFL TEACHERS' OPINIONS ON THE MPC MODEL

\begin{tabular}{lcc}
\hline Proble ms & $\boldsymbol{X}$ & SD \\
\hline $\begin{array}{l}\text { 1. The MPC Model can provide mult ilayered cooperation among teachers, that is, first } \\
\text { within the dyads, and then within the team. }\end{array}$ & 4.92 & 0.28 \\
2. The MPC Model can put all the heads together so that teachers can quickly deal with & 4.92 & 0.28 \\
the inexpected problems jumping from the realt eaching context. & 4.83 & 0.39 \\
3. The MPC Model emphasizes the process of professional development. & 4.83 & 0.39 \\
4. The MPC Model does not function the same as the teaching done by an individual teacher. & 4.92 & 0.29 \\
5. The MPC Model can be used to help new teachers to leam from more experienced colleagues. & 4.83 & 0.39 \\
6. The MPC Model can be used for experienced teachers to work togetherto understand & 4.92 & 0.28 \\
and implement a new curriculum. & 4.92 & 0.28 \\
7. The MPC Model can reduce the sense of isolation that teachers tend to feel. & & \\
8. The MPC Model provides opportunities fortwo teachersto identify teaching problems & 4.92 & 0.29 \\
and think of possible solutions, and then four teachers in the same team can share & 4.83 & 0.39 \\
their opinions on them. & $\mathbf{4 . 8 8}$ & $\mathbf{0 . 3 2}$ \\
9. The MPC Model is useful for updat ing teachers' professional knowledge and performance. & & \\
10. The MPC Model is an effect ive way to promote professional development in a sust ainable way. & & \\
Total & &
\end{tabular}


Table 2 showed the responses given by a total of 12 teacher participants. The results were displayed according to the item categories: process, target-group, and product. Items No. 1, 2, 3 and 4 took the MPC Model as the "process". With the mean scores of $4.92,4.92,4.83,4.83$ and the standard deviation of $0.28,0.28,0.39,0.39$ respectively, the teachers agreed that the MPC Model could provide the teachers with the multilayered cooperation, deal with the unexpected problems from the real teaching context, emphasize the process of professional development, and offer the different teaching process from that done by an individual teacher. Meanwhile, items No. 5, 6 and 7 were intended to the "target-group" including the teachers with the help of the MPC Model. The mean scores $(4.92 .4 .83,4.92)$ and the standard deviation $(0.28,0.39,0.28)$ of these items showed that the MPC Model could be used to help new teachers to learn from experienced colleagues, to help experienced teachers to work together for better teaching, and to reduce the teachers' sense of isolation. Furthermore, items No. 8, 9 and 10 referred to the "product" that the MPC Model produced. These item results showed the teachers' agreement with the mean scores of 4.92, 4.92, 4.83 and the standard deviation of $0.28,0.28,0.39$ that the MPC Model provided opportunities for the peer teachers to identify teaching problems, think of possible solutions, and then for the team teachers to share their opinions; in addition, the MPC Model was useful to update the teachers' professional knowledge and competence, and could sustain the teachers' professional development. Therefore, the teacher participants showed their positive attitudes towards the MPC Model from the results of these closed-end statements in the questionnaire.

Secondly, the open-ended questions in the questionnaire regarding the teachers' opinions on the MPC Model for their in-service professional development were also responded by all of the 12 teacher participants. The results were quite similar to those in closed-ended questions, which illustrated the teachers' positive opinions on the MPC Model.

\section{E. Results from the Interview}

The responses from the 12 teacher participants in the semi-structured interview to investigate their attitudes towards the MPC Model were presented below:

It was found that 10 of these 12 teachers took part in the professional cooperation for the first time, while 2 experienced it in some high schools once before. After implementing the MPC Model, all of them had a clear understanding of the definition of this model and of how to carry it out.

When it came to their opinions on the differences between the MPC Model and the traditional individual teaching, each of them gave their answer, and said the former was tremendously helpful in many aspects. Here was one example:

"...... certainly, there are a lot of differences between these two kinds of teaching models. As for me, I think, maybe, the biggest difference is that the multilayered model focused on the team work, in the team, the teacher, the dyads can exchange ideas, they work together, they can solve problems, they can share teaching methods, and something like that, so I think it is good. For the traditional individual teaching model, we can not say it's bad, but we can see it only depends on one teacher, he only can depend on himself, sometimes, maybe his idea is not, how to say, is not so profound, not good, not so diverse...... " (T4)

They also said that if they had the choice, they would choose the MPC Model for their in-service professional development. One of them gave her reason like this:

"I will choose this model. I think it can encourage our in-service professional development, sometimes when we reach one level, we stop here, we can not expand our ideas, can not expand our teaching methods, but when we use this kind of multilayered peer coaching practice, we work, we cooperate with each other, and the other teachers in your group can bring you new ideas, new teaching methods, so it certainly can enlarge our views, can expand our horizons and it is very helpful, for our professional development." (T5)

The interviewees also gave their responses to the question "Do you think the multilayered peer coaching practice can make your in-service professional development in continuity?" the following was some of their voices:

"......this model is quite useful and helpful in this area, for the professional development, the sustains and enthusiasm are most important ways, how to say, we find this model can be for professional development, to go on to help teachers with their professional development, and if we can train the key purpose that is involved in this model, I think it is definitely useful and helpful to sustain the professional development. " (T6)

“...yes, sure, the multilayered peer coaching model can contribute a lot to the in-service professional development in continuity. ... It seems that we hold some seminars by collaboration between the teachers in same university for our career, even between the colleagues. So this model provides more opportunities to discuss, to cooperate with each other in this sense, I'd like to call this model as another style of seminar or conference, very useful for us when we are in service." (T7)

While answering whether the MPC Model could deal efficiently with the problems arising from their classroom, they showed their uniform agreement. As one of them said,

"...Sometimes the problems are so unexpected, when I teach by myself, and I can find nobody to discuss with, sometimes I fail to solve it, and sometimes I solve it long after. But in the multilayered peer coaching model, the peer teachers' help, the team members' help can find the solution quickly or timely. What's more, we find we are strong or confident enough to deal with the situation with a team behind us..." (T7)

The teachers also gave the response to whether the MPC Model contributed to a better understanding between the colleagues, and all of them thought that by working together the teachers had more contact with their colleagues, which 
led to their better understanding of each other. Besides, many of them suggested that we should continue the MPC Model after the experimental teaching, and more courses could be involved.

To conclude, it could be said that after the teachers' cooperation in the MPC Model, their professional knowledge and teaching ability were kept improving in their daily work and their in-service professional development were implemented in a sustainable way.

\section{DISCUSSION}

According to the results presented above, the continuity of the tertiary EFL teachers' in-service professional development and their attitudes towards the MPC Model were discussed.

\section{A. The Continuity of the EFL Teachers' In-service Professional Development in the MPC Model}

The results from this study revealed that the problem that the tertiary EFL teachers failed to continue their in-service professional development was solved by applying the MPC Model to their in-service professional development. This happened because the MPC Model was characterized by putting the teachers' in-service professional development into their daily teaching in a cooperative way. The design of the MPC Model was helped theoretically by the constructivist principle "Activity Theory," which was largely based on Vygotsky's work. It theorized that when individuals engage and interact with their environment, production of tools results. These tools are exteriorized forms of mental processes, and as these mental processes are manifested in tools, they become more readily accessible and communicable to other people, thereafter becoming useful for social interaction and this process is known as internalization (Vygotsky, 1978). Learning takes place in social interaction in a specific context which comes internalized by a person (Hedegaard, 1998). Following Vygotskian theory, the teachers began to internalize the processes of their daily cooperation in teaching and research until they became an automatic part of their internal professional development activities. This implied that the MPC Model could help the teachers sustain their in-service professional development.

\section{B. The Advantages that Teachers Recognized to Cooperate for Their In-service Professional Development}

Based on the results from this study, the teachers agreed that their cooperation in the MPC Model helped them solve the problems in their in-service professional development. They preferred to work together with the peer teachers or team members in their daily teaching rather than work individually. Their mind seemed to be activated by working with colleagues in the MPC Model, more ideas conjured up frequently and more teaching strategies appeared in classroom teaching, what's more, they felt much more pleasant in the teaching team. This happened because the multilayered peer coaching offered the teachers the environment in which the peer teachers and the team members could work together for their teaching and research. In doing so, the teachers felt much stronger academically and more confident psychologically, which was line with what some other researchers found. Montaya et al (2009) pointed out that in teacher cooperation experience, the members of the group gives each other moral support and confidence, most of the teachers involved feel that they carried out their professional duties with greater feeling of confidence and with the backing of their colleagues. Johnson (1991) also stressed that through cooperation, lecturers satisfy personal needs, obtaining security and psychological support; they satisfy teaching needs, as they receive pedagogic advice; and they satisfy organizational needs on coordinating the students' learning. Dunne and Villani (2007) asserted that through the use of successful cooperative planning and organizational techniques, teams of classroom educators and ESL (English as a Second Language) teachers not only discover how to improve their lesson delivery and differentiate instruction for ELLs (English language Learners), but also offer peer support to each other and engage in formal or informal mentoring and peer coaching arrangements. This implied that the teachers' agreement with the advantages of the multilayered peer coaching was the first step for them to have or sustain in-service professional development by using the MPC Model.

\section{Factors Leading to the Teachers' Satisfaction with the MPC Model}

From the results of this study, the teachers expressed that by using the MPC Model it was much easier for them to conduct their teaching and learning. This happened because the MPC Model with its striking characteristics of putting peer coaching within a team teaching context facilitated the teachers' in-service professional development, and they could update their professional knowledge and teaching ability in their daily work rather than do it on purpose in a specific program. This was quite the same with some other researchers' work. For example, according to Leavitt (2006), everyone on the team has to be behind every element of the course, while reaching this consensus may take a lot of time and compromise, in the end the extra effort will result in a far more successful intellectual experience. Darling-Hammond and Richardson (2009) reviewed 20 years of research on effective teacher learning and professional development, examining the content, context, and design of high quality professional development. They concluded that teachers learn most effectively and easily when learning is collaborative and collegial, and professional development is intensive and sustained over time. They noted that the most successful framework for this type of professional learning for teachers is professional learning communities.

The teachers also expressed that by using the MPC Model they felt much more comfortable with their teaching and research. This happened because when the peer teachers and team members worked together, they had more contact with each other and had a better understanding of each other than before. Friendship made in their cooperation could 
encourage their learning interest, and the products or outcomes from their cooperative teaching and research could motivate their professional development as well. This was just consistent with some previous studies. Dove and Honigsfeld (2010) pointed out that when teachers engage in collaborative practices, they experience a reduction in isolation, enjoy more occasions to share their expertise, and appreciate the opportunity to shape the way the ESL program operates in their schools. This implied that the teachers in such a context were willing to continue their in-service professional development.

\section{CONCLUSION}

This study has been conducted to investigate the opinions of the tertiary EFL teachers on the MPC Model for their in-service professional development, and make the recommendation of this model for sustaining tertiary EFL teachers' in-service professional development. The results from this study have contributed to the field of research on EFL teachers' professional development. It was found that the MPC Model could help the teachers sustain their in-service professional development and the teachers had positive attitudes towards the MPC Model for their in-service professional development. Furthermore, further research can be conducted to help tertiary EFL teachers focus on the classroom research so that their classroom teaching can be guided by the relevant updated TEFL theories and principles. In doing so, their in-service professional development will be continued.

\section{ACKNOWLEDGMENT}

The authors wish to thank the experts from the universities in Thailand and China who helped to evaluate the MPC Model. They also want to thank the EFL teachers and the second-year English major students from Guiyang University, China, who were the main participants of this study.

\section{REFERENCES}

[1] Ball, D.L. \& Cohen, D.K. (1999). Developing practice, developing practitioners: toward practice-based theory of professional education. In L. Darling-Hammond \& G. Sykes (Eds). Teaching as the learning profession: handbook of policy and practice. San Francisco: Jossey Bass, 3-32.

[2] CERNET. (2001). Chinese Universities Enroll 2.6 Million Freshmen. Education in China. http://www.edu.cn/200111_1473 /20060323/t20060323_20256.shtml (accessed 28/2/2013).

[3] Collinson, V. \& Ono, Y. (2001). Professional development of teachers in United States and Japan. European Journal of Teacher Education, 24, 223-248.

[4] Darling-Hammond, L., \& Richardson, N. (2009). Teacher learning: What matters? Educational Leadership, 66(5), 46-53.

[5] Day, C. (1999). Developing teachers: The challenges of life-long learning. London: Falmer Press.

[6] Dove, M. \& Honigsfeld, A. (2010). ESL coteaching and collaboration: Opportunities to develop teacher leadership and enhance student learning. TESOL Journal, 1(1), 3-22.

[7] Dunne, K., \& Villani, S. (2007). Mentoring new teachers through collaborative coaching: Linking teacher and student learning. San Francisco: WestEd.

[8] Fessler, R., \& Christensen, J. (1992). The teacher career cycle: Understanding and guiding the professional development of teachers. Boston: Allyn and Bacon.

[9] Feiman-Nemser, S. (2001). From preparation to practice: designing a continuum to strengthen and sustain teaching. Teachers

[10] College Record, 103, 1013-1055.

[11] Fullan, M. \& Hargreaves, A. (1996). What's worth fighting for in your school. New York: Teachers College Press.

[12] Hedegaard, M. (1998). Situated learning and cognition: Theoretical learning and cognition. Mind, culture, and actvitity, 5 (2), 114-126.

[13] Huberman, M. (1993a). Steps towards a developmental model of the teaching career. In L. Kremer-Hayon, H. Vonk, \& R. Fessler (Eds.), Teacher professional development: A multiple perspective approach. Amsterdam: Swets and Zeitlinger, 93-118.

[14] James, L. (1973). The James Report's Third Cycle. In In-Service Training: Structured Context, Watkins, (Eds.) London: Ward Lock Educational.

[15] Johnson, D. W., Johnson, R.T. \& Smith, K.A. (1991). Cooperative Learning: Increasing College Faculty Instructional Productivity, Washington D.C.: The George Washington University.

[16] Leavitt, M. C. (2006) Team teaching: Benefits and challenges. Speaking of Teaching. 16(1), 1-4.

[17] Liu, G. Z. (2005). The trend and challenge for teaching EFL at Taiwanese universities. Regional Language Centre Journal, $36(2), 211-221$.

[18] Liu, X. (2006). Exploration of issues and models of new curriculum training for rural junior high school English teachers, Foreign Language Teaching and Research in Basic Education, 70(12), 51-53.

[19] McGriff, S. J. (2000). Instructional Systems, College of Education. Penn State University.

[20] Montaya, M.G., Gil, C.M., Montaya, F.G., \& Alias, A. (2009). The importance of cooperative work in the faculty and the classroom. In W, Kouwenhoven (Eds). Advances in Technology, Education and Development, Spain: Valencia, 264-280.

[21] Ono, Y. \& Ferreira, J. (2010). A case study of continuing teacher professional development through lesson study in South Africa. South African Journal of Education, 30, 59-74.

[22] Schwille, J. \& Dembélé, M. (2007). Global perspectives on teacher learning: improving policy and practice. Paris: UNESCO International Institute for Educational Planning.

[23] Tsui, A. B.M. (2007). What shapes teachers' professional development? In J. Cummins, \& C. Davison (Eds). International Handbook of English Language Teaching. New York: Springer Science + Business Media, LLC, 1053-1066. 
[24] Villegas-Reimers, E. (2003). Teacher professional development: an international review of the literature. Paris: UNESCO International Institute for Educational Planning.

[25] Vygotsky, L.S. (1978). Mind in society. Cambridge, MA: Harvard University Press

[26] Wan, W.Y. (2011). Teachers' Perceptions and Experiences of Continuing Professional Development(CPD): Opportunities and Needs in Hong Kong Primary Schools. Ph.D Dissertation, University of Nottingham.

[27] Wen, Q.F. \& Ren, Q.M. (2010). On the tertiary EFL teacher in-service professional development in China: Trends, Characteristics, Problems and Solutions -- By reviewing the related literature from 1999 to 2009. FLC. 7(4), 77-83.

[28] Widden, M.F., Mayer-Smith, J.A., \& Moon, B.J. (1996). Knowledge, Teacher Development and Change. In Teachers' Professional Lives, In I. F. Goodson \& A. Hargreaves (Eds.). London: Falmer Press, 187-205.

[29] Zhang, Z. \& Li, S. (2003). English teacher development, Curriculum, Teaching Material and Method, 23(11), 59-66.

[30] Zheng, H.Y. (2010). Dilemmas in Teacher Development in the Chinese EFL Context. Journal of Cambridge Studies, 7(2), 2-13.

Junyi Meng is a Ph. D candidate in English Language Studies at School of Foreign Languages in Institute of Social Technology of Suranaree University of Technology, Thailand. She received her MA degree in Master of Art in Teaching from Oakland University, Michigan, USA, in1998. She is a faculty member of School of Foreign Languages at Guiyang University, Guizhou, China. Her research interests include TEFL and teacher training.

Songphorn Tajaroensuk is an associate professor of School of Foreign Languages, Institute of Social Technology, Suranaree University of Technology (SUT), Thailand, and she is the former Dean of Institute of Social Technology, SUT. She obtained her M.A. in English at Chulalongkorn University, Thailand, and M. A. in TEFL at Southern Illinois University, USA. She has been teaching and supervising MA and Ph. D students in English Language Studies for more than ten years. Her research field is TEFL and teacher training.

Sirinthorn Seepho is a lecturer of School of Foreign Languages, Institute of Social Technology, Suranaree University of Technology (SUT), Thailand, She obtained her M.A in Applied Linguistics at King Mongkut's University of Technology, Thonburi, Thailand, and her Ph.D. degree in Foreign Languages Education at University of Pittsburgh, Pennsylvania, USA. She has been teaching and supervising MA and Ph. D students in English Language Studies at SUT. Her research field is TEFL and teacher training. 